\title{
Low Impact Development and Transportation in the City of Mesa, AZ
}

\author{
Maria Angelica Deeb ${ }^{1}$ \\ ${ }^{1}$ Transportation Department, City of Mesa, Mesa, Arizona \\ Correspondence: Maria Angelica Deeb, Transportation Department, City of Mesa, P.O. Box 1466 ZIP \\ 85211-1466, Mesa, Arizona. Tel: 1-480-644-2845. E-mail: Maria.Deeb@mesaaz.gov
}

Received: October 14, 2015

Accepted: November 9, $2015 \quad$ Online Published: November 26, 2015

doi:10.5539/jgg.v7n4p65

URL: http://dx.doi.org/10.5539/jgg.v7n4p65

\begin{abstract}
The Cities of Mesa and Glendale, with a grant from the Water Infrastructure Finance Authority of Arizona (WIFA), partnered and developed a Low Impact Development (LID) Toolkit. This toolkit is a 100 page document that responds to the need to better manage the storm water runoff and reduce the need for very expensive expansion of drainage infrastructure. The solution to this problem justifies the need to use LID in Mesa. In 2014 the City of Mesa experienced flooding which affected many. Although LID solutions was considered at the time of this flooding event, it became a priority to identify potential solutions. The LID toolkit responded to this and is intended to minimize the harmful impacts of flooding by setting best practices related to the management of the rainfall-runoff process. The LID toolkit identifies and lists best storm-water City of Mesa management practices and national and regional LID best practices. This list and publication is intended to encourage City and private planners, designers and residents alike towards the practice of more sustainable design. The article presents the history of LID design and discusses the benefits of using LID tools.
\end{abstract}

Keywords: best practices, low impact development (LID) toolkit, storm-water management, sustainable design practices, transportation

\section{Introduction}

Low Impact Development (LID), as defined in the Low Impact Development Toolkit document prepared by the City of Mesa and by their consultant team Logan Simpson "is a sustainable approach to storm-water management that utilizes the landscape to absorb storm runoff, reducing offsite flows that can contribute to flooding and infrastructure costs." (LID Toolkit, 1) Some other benefits include pollution reduction and aesthetic improvements. "The goal of LID is to mimic and sustain predevelopment hydraulic regime by using techniques that are included in this Toolkit. LID tools can be used to divert, store and utilize storm-water runoff to support native and designed landscapes." (LID Toolkit, 1) The LID Toolkit lists best management practices for the desert southwest. Low impact development is a requirement of Mesa's municipal storm-water permit issued by the Arizona Department of Environmental Quality.

\section{Method: Development of the Toolkit}

In 2014, the City of Mesa experienced flooding which affected many. Although LID solutions been considered prior to this flooding event, it became a priority to identify potential solutions. Management of storm-water runoff is directly related to how land is developed or/and improved.

By detaining storm-water close to its source, one could potentially reduce runoff volume and velocity downstream. By collecting sediment and reducing pollutants, the storm-water runoff is less of an environmental concern. By utilizing storm-water to support native vegetation and landscape improvements, benefits may occur. The LID toolkit responded to the need to better management of runoffs, and was intended as a document that identified tools that help minimize the harmful impacts of flooding by setting best practices related to the management of the rainfall-runoff process. The LID toolkit identifies and lists best storm-water City of Mesa management practices and national and regional LID best practices. 


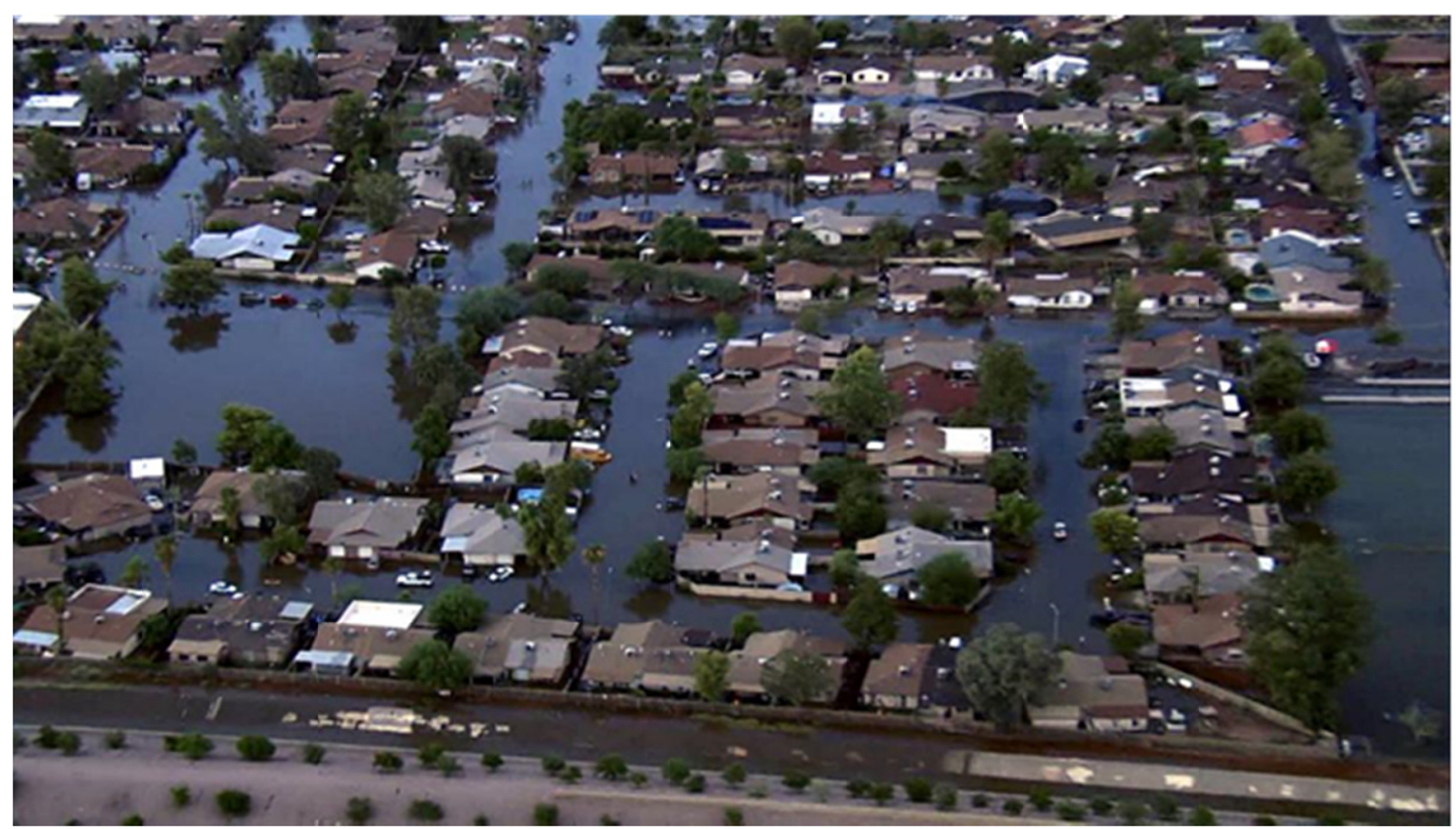

Figure 1. 2014 Flooding - City of Mesa, Arizona

Transportation projects have the potential to assist with better management of water if managed close to its source. Projects may also provide reductions of runoff volume and velocity downstream if the implementation and construction of these projects includes LID proper drainage infrastructure, installation of medians that include native vegetation and landscape improvements, and irrigation systems that are true to the LID concepts. When LID is brought forward to the Transportation field, the implementation of potential actions addressed in the LID Toolkit are beneficial and possible as the LID is adaptable to a wide range of land uses and project scales (LID Toolkit, 1).

\subsection{Start of LID}

Development of LID principles in the United States of America began in the mid-1980s with the introduction of bio-retention technology in Maryland. LID helped Prince George's County identify and formulate solutions for problems related to the mishandling of the County's economic growth and mis-use of their existing environmental resources when implementing conventional storm-water management practices. The use of LID resulted in allowing the County for greater development potential with less environmental impacts. LID brought opportunities for the development and use of designs and advanced technologies that achieved a better balance between conservation, growth, ecosystem protection, and public health / quality of life. (http://www.lid-stormwater.net/background.htm, 10/7/2015).

Today, bio-retention is just one of the LID tools that is available to use. Other tools, such as permeable pavers, tree box planters, and disconnected downspouts, help users control pollutants, reduce runoff volume, manage runoff timing, and address a number of other ecological concerns.

\subsection{Why Use LID?}

The LID community states that LID "is a more environmentally sound technology and a more economically sustainable approach to addressing the adverse impacts of urbanization. By managing runoff close to its source though intelligent site design, LID can enhance the local environment, protect public health, and improve community livability - all while saving developers and local governments money. The need for such an approach has never been greater." (http://www.lid-stormwater.net/background.htm, 10/7/2015)

The LID community also states the benefits based on compliance of regulations; these regulations being federal, state or local. Storm-water programs require that environmental and health protection goals be achieved while working in complex systems. Many of these goals are not easily met and can be very costly by the use and implementation of conventional storm-water management technology. Furthermore, communities do not have 
the funds to upgrade or expand, or have limits to the use of funds to address the maintenance of aging storm-water infrastructure. Many communities that are densely populated and the population center has developed in watersheds, struggle with how to restore stream quality in these watersheds. Most communities find themselves not being able to rely on conventional ways to address such issues as water runoff, water quality or drainage management. The conventional ways prove, most of the time, to be not feasible, practical, cost effective or sustainable for solving these issues.

Literature has identified specific benefits to LID, and these are listed below:

- As a regulator LID can provide options to address a wide range of Wet Weather Flow issues, including Combined Sewer Overflows (CSOs), National Pollutant Discharge Elimination System (NPDES) Stormwater Phase II permits, Total Maximum Daily Load (TMDL) permits, Nonpoint Source Program goals, and other Water Quality Standards.

- Local permitting agencies can use LID to support local zoning and subdivision regulations and revise these if necessary, so they become more cost-effective and ecologically sound development practices.

- Developers and contractors can use LID tools that result in projects more successful as they provide owners and users with cost savings.

- Designers and planners (city and private) can use LID principles so their projects are more innovative, educational, and include more aesthetically pleasing sites.

The benefits listed above have been discussed at a national level. The website "Low Impact Development (LID) Urban Design Tools" (http://www.lid-stormwater.net/) provides a set of tools and techniques that "can be used to meet regulatory and receiving water protection program goals for urban retrofits, re-development projects, and new development sites." (http://www.lid-stormwater.net/, 10/7/2015) The site was developed through a Cooperative Assistance Agreement under the US EPA Office of Water 104b(3) Program in order to provide guidance to local governments, planners, and engineers for developing, administering, and incorporating LID into their water and water-shed resource protection programs.

LID can be used in a number of different settings and implemented in urban and residential areas, as well as in transportation projects. The City of Mesa has developed ways and strategies for the use of LID within their City and assets. In order to follow LID concepts, one must plan and design infrastructures that affect the hydrologic regime of development.

The tools included in the document are categorized within, and these categories are based on the man-made storm-water run-off that is to be managed, or the "source" of the storm-water run-off. Once the source is defined, the method used to manage such source is listed in the "action" row and may be used to further categorize such tools. Once the source and action are identified, the available and best practices LID tools are listed in the "Tools" row. The different implementations of these current and available tools are listed below the specific tool under "technical variations". The following diagram shows an example of such categorization. The specific source been addressed in the example provided is the storm-water runoff originated in parking lots and streets.

The tools included in the document were collected, reviewed and defined from many sources including "research of professional organizations, onsite observation and research of data provided by cities and other sources. The Environmental Protection Agency (EPA) has published several guides to LID that describe the various LID methods that have been developed and implemented throughout the country. Not-for-profit interest groups such as the Watershed Management Group, have documented several examples that have been implemented in the desert Southwest." (LID Toolkit, 7)

The implementation of the LID best management practices require special attention to and must address site and project specific needs as well as existing conditions. Only within the "appropriate site and project context, LID tools can be effectively deployed to achieve cities' storm-water management goals." (LID Toolkit, 7) 


\section{LID TOOLKIT DIAGRAM}

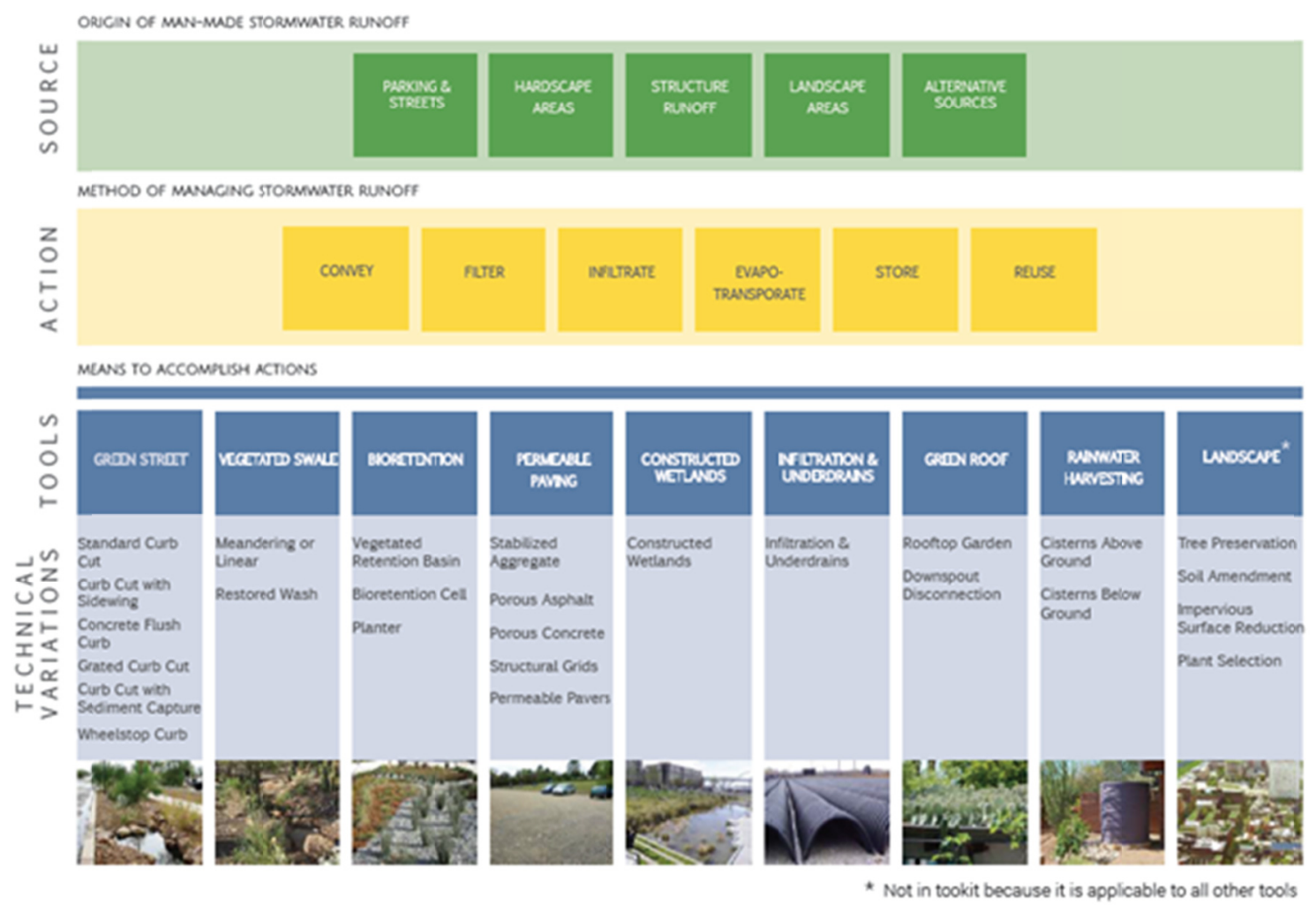

Figure 2. LID Toolkit Diagram, Source: Low Impact Development Toolkit, 6

Some of the LID tools are specific to certain locations and types of development. Transportation projects have a huge part to play in the implementation of best management practices, as many of these may be included in the scope of work of what gets designed and implemented. Included below is a diagram of the some of the toolkit proposals that may be included in transportation projects. However, the tools will only be beneficial if their design, implementation and maintenance also includes LID concepts.

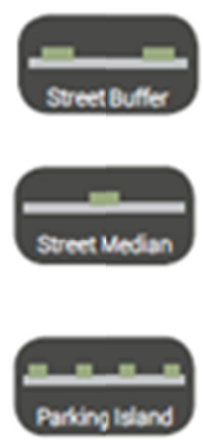

Street Buffer

-landscaped area

between street and building

\section{Street Median}

-distinct island

in middle of road designed to guide traffic

Parking Island

- distinct island in

parking area designed

to guide traffic

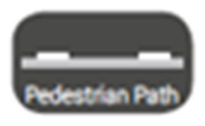

Pedestrian Path

-designed walkway for pedestrians

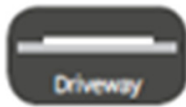

Driveway

- private vehicular

accessway

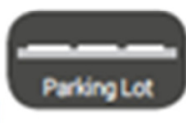

Parking Lot

-designated area for parking

Figure 3. Location specific LID tools for Transportation, Source: Low Impact Development Toolkit, 8

The LID Toolkit was developed in such a way that the LID tools included are identified by the specific function they serve as related to storm-water management. Some LID tools can perform several functions. The functions are identified graphically and this depiction is intended to allow city staff, designers, planners (private or public) 
and residents alike determine the function to manage. This function, therefore determines the tools available to them for implementation and to include in their LID design and construction.

The functions included in the LID Toolkit are depicted in Figure 4.

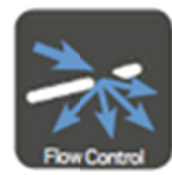

Flow Control -the regulation of stormwater runoff flow rates.
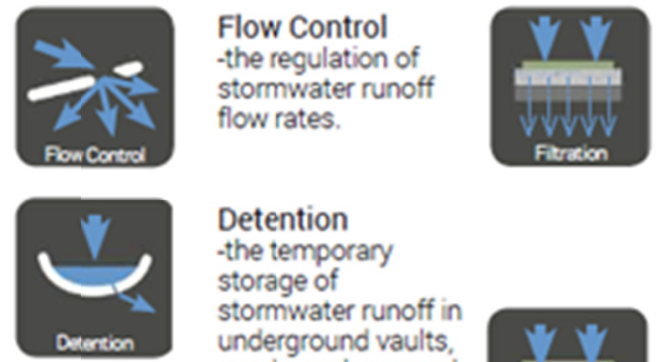

Detention

-the temporary

storage of

stormwater runoff in underground vaults, ponds, or depressed areas to allow for metered discharge that reduce peak flow rates.

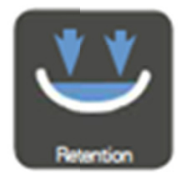

Retention -the storage of stormwater runoff on-site to allow for sedimentation of suspended solids.

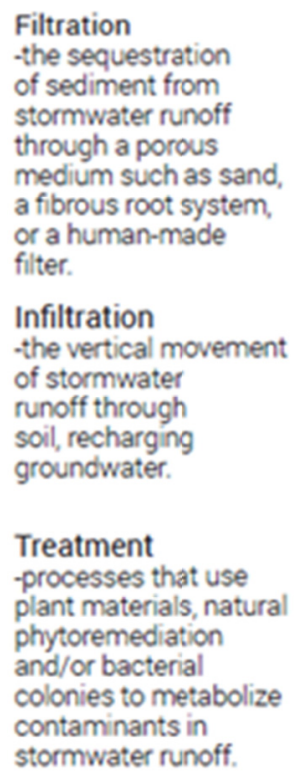

Treatment

-processes that use

plant materials, natural

phytoremediation

and/or bacterial

colonies to metabolize

contaminants in

stormwater runoff.

Figure 4. Functions specific to LID tools, Source: Low Impact Development Toolkit, 8

The benefits of the LID tools are also represented with icons that allow the identification of the indirect benefits associated with each LID practice.
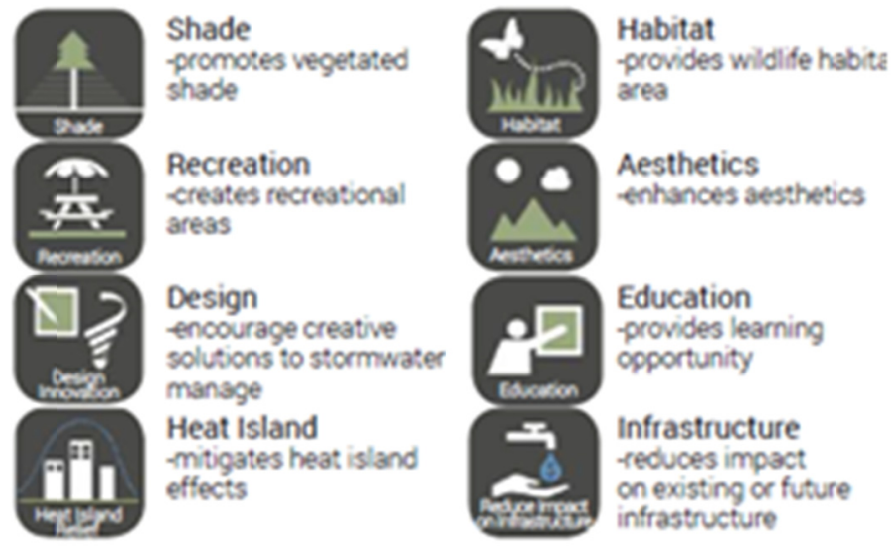

Figure 5. Benefits specific to LID tools, Source: Low Impact Development Toolkit, 8

Each tool has its own page in the LID Toolkit document and it includes a description of the type of tool, the materials suggested to be used to construct or implement and potential uses of the tool. It also includes a section for the most common installation methods. These methods are intended to be "live", therefore may be improved in the future publications of the LID Toolkit by the City of Mesa. Improvements may be expected when best practices are furthered refined, or the installation methods are modified so they are consistent with City of Mesa standards and guidelines. Also included in the LID Toolkit page is a description of their maintenance which lists ways to include criteria for the tool's long term functionality.

The following diagram shows, one of the pages discussed above. 

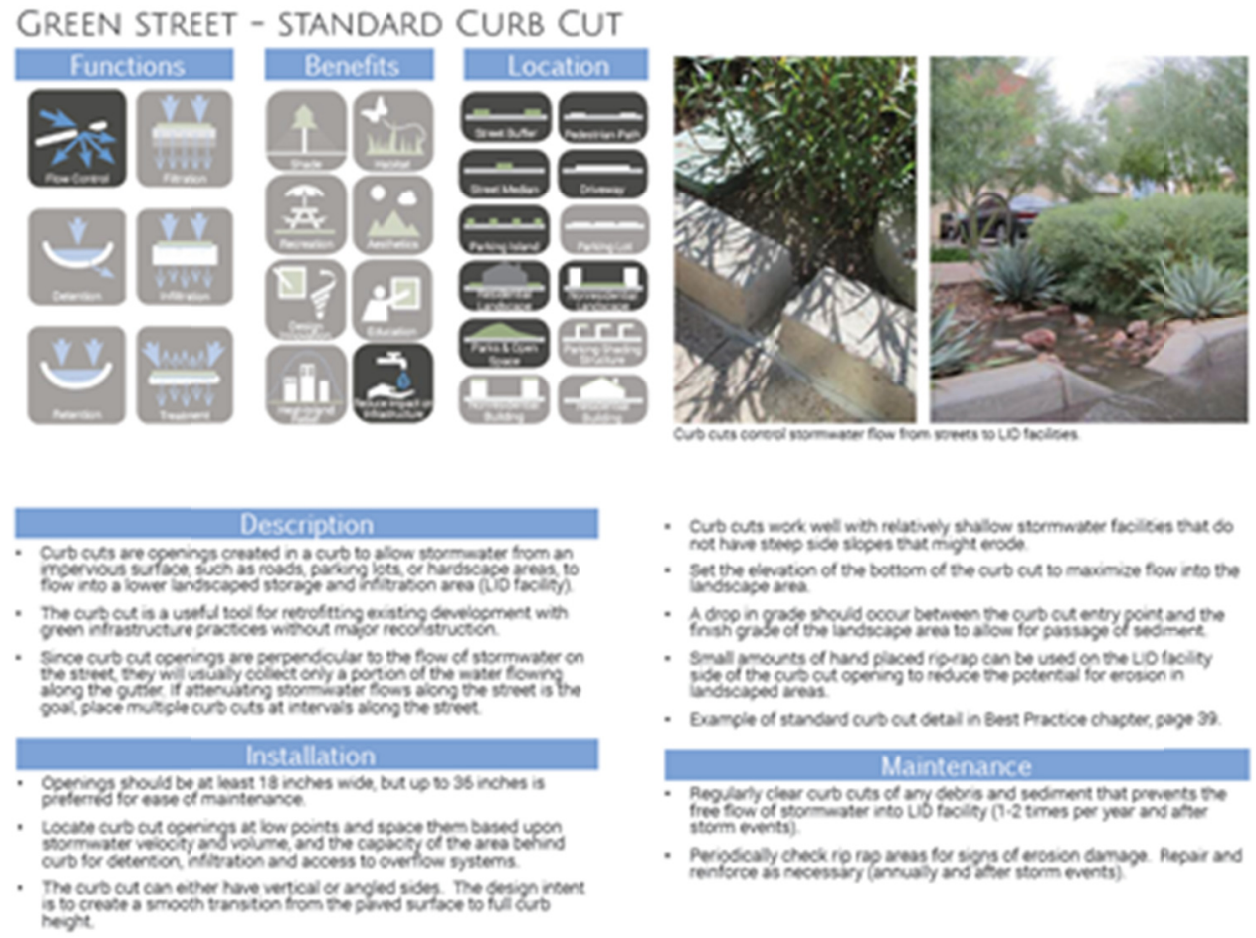

Figure 6. LID tool page - Green Street - Standard Curb Cut, Source: Low Impact Development Toolkit, 10

\section{Results}

The LID Toolkit has solved the desire to include LID concepts in City of Mesa projects. The toolkit provides a list of design items that when implement will help manage the rainfall-runoff process. The LID toolkit identifies and lists best storm-water management practices to be incorporated in City projects. The City of Mesa is encouraging the use of LID tools. The City has adopted a modified form of Maricopa Association of Governments (MAG) standards for guiding development policy and implementing public works projects. The Toolkit includes best practices that are currently being studied. The City is Mesa is leading by example, and is providing "funding for pilot projects in highly visible areas to increase public awareness, by updating and supporting policies that encourage more sustainable storm-water management, and by considering the integration of LID into all municipal projects." (LID Toolkit, v) The City is also educating the public and other government staff, as it did when presenting the LID Toolkit at the Sustainable Cities Network on April 16, 2015 or it is going to do at the 2016 Roads and Street Conference (Tucson, Arizona).

The LID Toolkit was developed to assess current construction methods, and to determine how and when LID tools and methods should be used to improve storm-water management. This is an on-going effort.

The LID Toolkit has encouraged the City of Mesa to review and assess current city policies, codes, regulations and checklists to determine what updates are needed to enable and encourage the implementation of LID techniques. The City's Environmental and Sustainability division, part of Mesa's Environmental Management and Sustainability Department together with the Transportation Department, ensure that the Mesa residents are provided with a clean, safe and environmentally sound community. The City's Environmental and Sustainability division ensures that the City operations, such as those of the Transportation Department, comply with all federal, state and local environmental regulations. For additional information, please follow this link: http://mesaaz.gov/residents/environmental

A common concern is that LID-based projects will be more expensive because they could require higher design and construction costs and a longer time to receive project approval. This depends on the experience of the project consultants and contractors with LID techniques and LID tools, and the receptiveness of local government officials to innovative practices. These potential cost increases do not mean that the concept of LID should not be implemented; these costs may steam from inexperienced institutions, individuals, and bureaucracies that remain unaware of the necessity for and benefits of the LID approach. This is changing and it is being done in the desert southwest! For example, several years ago there were only a few permeable paver 
options available. Today, the consumer can choose from a large number of these materials, and more widespread usage and acceptance of the technology has led to lower costs.

Additional LID cost concerns include the potential for greater expenses due to the increased use of on-site landscaping material. Despite these issues, experience has shown that LID still saves money over conventional approaches through reduced infrastructure and site preparation work. Case studies and pilot programs show at least a $25 \%$ to $30 \%$ reduction in costs associated with site development, storm-water fees, and maintenance for residential developments and transportation infrastructure that use LID techniques. These savings are achieved by reductions in clearing, grading, pipes, ponds, inlets, curbs and paving. Far outweighing any of the cost increases due to the use of LID, these infrastructure reduction savings enable builders to add value-enhancing features to the property, to be more flexible and competitive in pricing their products, or even to recover more developable space since there is no need to waste land for a storm-water pond.

Individual site characteristics and designs will be determining factors of actual costs. Some cost benefits of LID projects that have been documented include (terms as described in the http://www.lid-stormwater.net/background.htm, 10/7/2015):

1. Multi-functionality - In many projects the LID practice is designed but serves multiple purposes (such as with landscape and storm-water control as functions). In some situations, the landscaping cost encompasses the construction costs for storm-water, therefore one or the other is essentially free. In the operation of the system, the cost of maintaining the landscaped areas is an integral part of the Operations and Maintenance costs associated with the project, so the only additional costs for storm-water maintenance is to ensure that drainage areas are kept clear.

2. Lower lifetime costs - According to LID literature many "LID techniques are self-perpetuating, easily repairable, or can be left as natural areas at the end of their functional lifetime." (http://www.lid-stormwater.net/background.htm, 10/7/2015)

3. Additional environmental and social benefits - Some non-cash benefits are associated to the increase of the urban forests/deserts, reduction of the urban heat island, improvements to air quality, reduction of thermal stream pollution, enhancement of the appearance of a community, and provision of a stronger sense of place. These all are costs that benefit the community that embraces LID tools.

4. Functional use of open space land - LID practices, such as rain gardens, can usually be designed as part of the development's open space, without any loss of developable area. The City of Mesa has embraced this as seen in an article published November 13, 2014. 


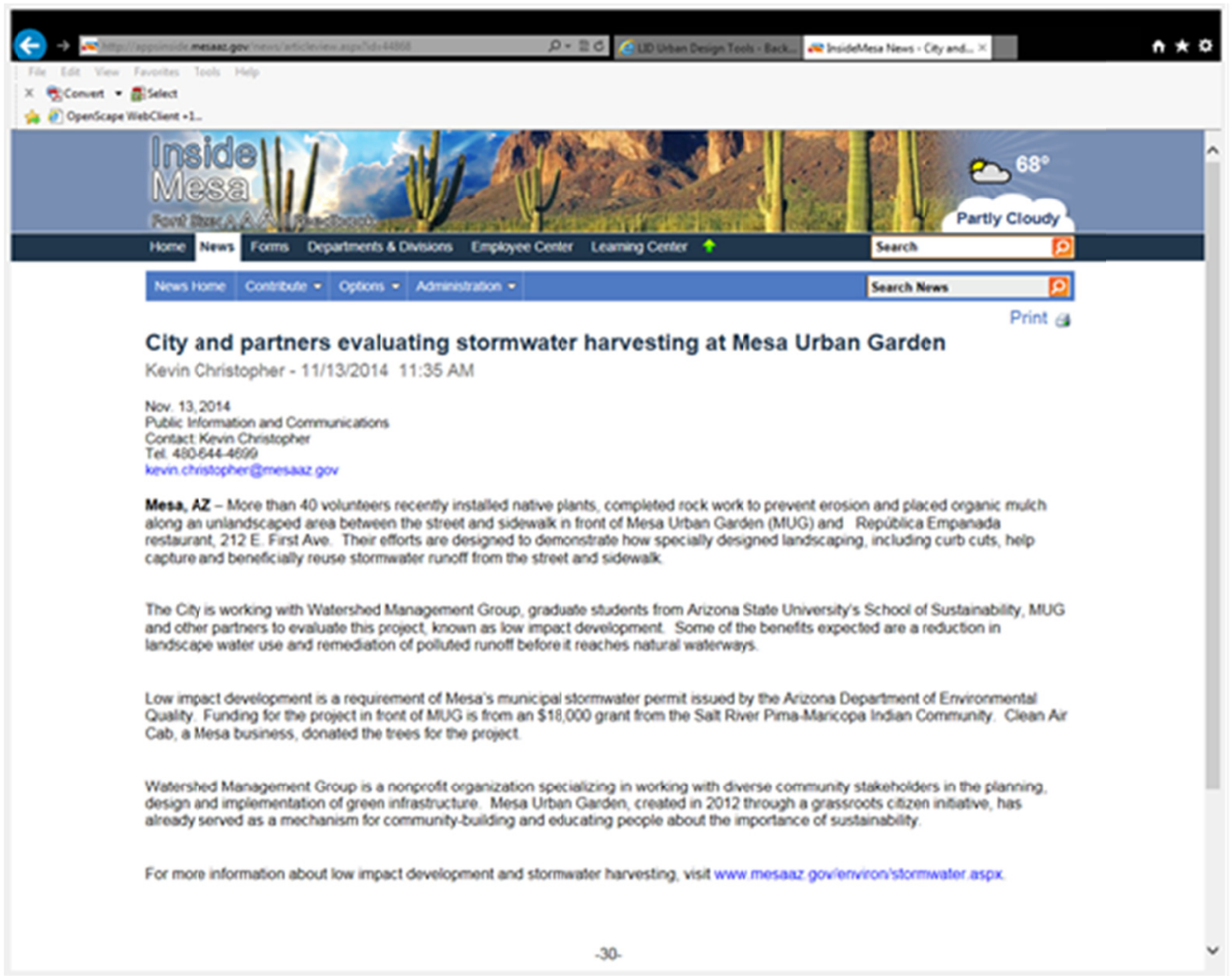

Figure 7. Inside Mesa news -City and partners evaluating storm-water harvesting at Mesa

\section{Conclusion}

As related to the statement of the problem, the publication of the City of Mesa LID Toolkit provided a document that responds to the need to better manage the storm water runoff and reduce the need for very expensive expansion of drainage infrastructure. For the LID Toolkit to maintain its relevance, the document must be treated as a living document that must be improved when more-best practices are studied. This document must also be improved when better ways of design, installation or maintenance of the tools already depicted within are identified. This is an effort all should embrace. All public works developed by the City of Mesa and others have the potential to becoming case studies for the LID Toolkit. All project managers and lead departments should include in the project's development and closeout an evaluation regarding the use and development of LID tools.

Furthermore, the public should also provide the City with case studies. Partnership with research universities or colleges is further encouraged.

Two tips for identifying the LID tools to use are listed. Future research may increase this list.

- There has got to be a better way. Everyone should be thinking of best ways to do things, and not just do them because it was previously done that way.

- Site specific conditions dictate what will work. We all have the responsibility to study and become ultimately familiar with the context and environment that defines the work site. Only by identifying what we are to use and what we are to solve, can we properly use the LID Toolkit.

Also LID talking points need to be developed so that all have consistent information and these may be used to educate the community at large. Some "talking points" to consider are listed below:

- LID is simple and effective. Instead of large investments in complex and costly centralized conveyance and treatment infrastructure, LID allows for the integration of treatment and management measures into urban site features.

- LID is economical. It costs less than conventional storm-water management systems to construct and maintain, in part, because of fewer pipes, fewer below-ground infrastructure requirements, and less imperviousness. 
- LID has many benefits. The greater use of on-lot multi-purpose landscaping / vegetation also offers human "quality of life" opportunities by greening neighborhoods and contributing to livability, value, sense of place, and aesthetics. Other benefits include enhanced property values and re-development potential, greater marketability, improved wildlife habitat, thermal pollution reduction, energy savings, smog reduction, enhanced wetlands protection, and decreased flooding.

- $\quad$ LID is flexible. It offers a wide variety of structural and nonstructural techniques to provide for both runoff quality and quantity benefits. LID works in highly urbanized constrained areas, as well as open regions and environmentally sensitive sites.

- LID is a balanced approach. LID is an advanced, ecologically-based land development technology that seeks to better integrate the built environment with the natural environment. LID's principles and practices allow the developed site to maintain its predevelopment watershed and ecological functions.

\section{References}

City of Mesa. (2015). Low Impact Development (LID) Toolkit.

Coffman, L. S. (2001). Low Impact Development creating a storm of controversy. Water Resources Impact, 3(6), 7-9. Retrieved from http://www.awra.org

Construction Industry Research and Information Association (1995). Infiltration drainage-appraisal of costs. Project Report 24. (London)

Puget Sound Water Quality Action Team's. (2015). Retrieved from http://www.psat.wa.gov/Programs/LID.htm

Urban Design Tools. (2015). Low Impact Development. Retrieved from http://www.lid-stormwater.net/index.html

\section{Copyrights}

Copyright for this article is retained by the author(s), with first publication rights granted to the journal.

This is an open-access article distributed under the terms and conditions of the Creative Commons Attribution license (http://creativecommons.org/licenses/by/3.0/). 